\title{
INDAGAÇÕES E PERSPECTIVAS DE MUDANÇAS PARA UM WEBCURRÍCULO
}

\author{
VALDIR ROSA \\ Universidade do Minho (U.Minho), Braga, Portugal
}

\begin{abstract}
REsUmo: Este artigo apresenta reflexões sobre a integração das tecnologias ao currículo a partir das concepções e teorias curriculares e da busca da compreensão dos significados de termos como integrar e inovar, com o objetivo de ampliar as discussões e direcionar para o alcance de um webcurrículo. Salienta-se ainda que, para alcançar essa meta, é necessário o investimento do poder público em dois domínios: na estrutura tecnológica das escolas e em uma adequada formação do professor. Entretanto, pontua-se que para uma formação adequada, é necessário ser baseada nos três níveis de conhecimento (pedagógico, tecnológico e de conteúdo) e nas teorias críticas e pós-crítica do currículo.

Palavras-chave: Webcurrículo. Teorias curriculares. Integração. Tecnologias.
\end{abstract}

INTRODUÇÃO $^{1}$

O desenvolvimento, nas últimas décadas, da tecnologia pela Ciência nas últimas décadas e a criação de artefatos tecnológicos cada vez mais sofisticados pela indústria eletrônica faz com que o mundo se encontra em constante e rápida transformação. Tal transformação, por meio das Tecnologias Digitais de Informação e Comunicação (TDIC), ocorre em todos os segmentos da sociedade, independente da classe social, raça ou credo.

Além disso, atualmente o mercado disponibiliza à população inúmeras maneiras para obtenção de um dispositivo móvel que pode ser, por 
exemplo, um laptop, um ipad, um iphone ou até mesmo um tablet. Nessa direção, os artefatos tecnológicos se fazem presentes nos diversos meios sociais e modificam hábitos, costumes e a forma de interagir de milhares de pessoas em todo mundo, o que os torna recurso indispensável para comunicação e busca de informações. Assim, no contexto em que se apresentam, tais tecnologias passaram a ser parte integrante da cultura (ALMEIDA; SILVA, 2011).

Da mesma forma, as TDIC se fazem presentes nos meios escolares, sendo que, na maioria das vezes, são utilizadas mais por alunos do que por professores, além de que, segundo Almeida e Valente (2012), seu potencial tecnológico para uso na Educação ainda é pouco explorado. Em contrapartida, abre-se uma série de debates e discussões acadêmicas que vão muito além do por quê? para quê? e como? utilizar as tecnologias na educação, mas havendo, contudo, a "necessidade de constituir a escola como espaço e ambiente educativos que ampliem a aprendizagem" (MOREIRA, 2007, p. 7). É necessário que a escola possa "preparar-se para bem socializar os conhecimentos escolares e facilitar o acesso do(a) estudante a outros saberes" (MOREIRA, 2007, p. 20) em qualquer ano de escolaridade.

Acredita-se que as TDIC se apresentem como meios para alcançar os objetivos de facilitar a aprendizagem e acessar os diferentes saberes e níveis de conhecimento. Nessa perspectiva, pretendeu-se, com o estudo apresentado neste artigo, trazer à tona indagações sobre a integração das tecnologias digitais ao currículo a partir de reflexões sobre a evolução da concepção curricular, no sentido de ampliar essas discussões para um caminhar em direção ao webcurrículo².

Teve-se a intenção, com as reflexões ora expostas, compreender que a integração das tecnologias educacionais ao currículo podem ser promovidas a fim de o transformá-lo em um webcurrículo. Entende-se que as tecnologias educacionais possam ser instrumentos utilizados para transformar os "meios" na intenção de atingir determinados "fins". Nesse sentido, torna-se necessário "conceber, gerir e avaliar os processos de ensino e aprendizagem" (COUTINHO, 2007, p. 1) em função dos objetivos propostos para atingir a aprendizagem. Igualmente se considera que essa abordagem vai ao encontro do que preconiza Miranda (2007) ao englobar todos os processos de concepção, desenvolvimento e avaliação da aprendizagem.

Adotou-se a abordagem qualitativa com procedimentos da pesquisa bibliográfica. De acordo com Cervo e Bervian (1983, p. 55), a pesquisa bibliográfica incide na explicação de "um problema a partir de referenciais teóricos publicados" e segundo Marconi e Lakatos (2007, p.185), embora se 
traduza no conhecimento das publicações existentes, "propicia o exame de um tema sob novo enfoque ou abordagem, chegando a conclusões inovadoras". Para análise, teve-se como aporte teórico os estudos de autores que versam sobre a formação de professores, integração das TDIC ao currículo e as teorias curriculares críticas.

\section{CONCEPÇÕES E TEORIAS SOBRE CURRÍCULO}

Encontrar um conceito único, fechado e definitivo para o termo"currículo" é uma tarefa com alto grau de complexidade. Isto porque há diversas definições na literatura, fato que envolve certa complicação e sua construção conceitual. Ademais, os conceitos "têm variado no tempo e no espaço" (BARRETO, 2006, p. 2) e estão permanentemente em desenvolvimento (RIBEIRO, 1990). Moreira (2007) reforça essa visão e esclarece que a dificuldade tem origem nos "diversos modos de como a educação é concebida historicamente, bem como nas influências teóricas que a afetam e se fazem hegemônicas em um dado momento" (p.17).

Assim, falar sobre currículo torna-se um grande desafio. Dentre as distintas definições e pensamentos sobre o que o currículo representa, muitos autores trazem diferentes contribuições para a sua interpretação. Ribeiro (1990), por exemplo, apresenta o currículo como um plano estruturado de ensino e aprendizagem que inclui três fatores específicos: os objetivos, os conteúdos e os processos de ensino, enquanto que Silva (2007) o vê como resultado de seleção dos elementos da cultura. Já para Sacristán (2010), o currículo é uma seleção de conteúdos e objetivos para ensinar e aprender, regulamentado pela prática didática que se desenvolve no contexto escolar.

Observa-se que, ao passar dos anos e com a evolução dos estudos direcionados à área curricular, as concepções sobre o currículo se alteraram, conceitos mais simples foram agregados na tentativa de abranger um significado com um grau maior de complexidade. Sob essa ótica, Pacheco (2005, p. 32) argumenta que o currículo é"transportado desde uma concepção restrita de plano de instrução até uma concepção aberta de projecto de formação".

Em 1918 foi publicado o livro "The curriculum", escrito pelo pesquisador Franklin John Bobbitt (1876-1969). Com base nas teorias de Taylor (1911) sobre os princípios da administração científica, Bobbitt imaginou o currículo preparado para o aluno seguindo os mesmos moldes utilizados na indústria em que se assume o controle burocrático do conhecimento e de sua organização (PACHECO, 2005). Essa concepção de currículo, visão tradi- 
cional, busca garantir que a escola funcione como uma fábrica, caracterizado pela divisão de disciplinas (ZABALA, 1998) e apresenta objetivos precisos, procedimentos e métodos, que possam ser validados com uma avaliação rigorosa da aprendizagem.

Os estudos de Tyler (1949), por sua vez, apresentam uma constituição de currículo tecnicista com base na administração científica (SILVA, 2006) e culminam no que foi reconhecido como teoria da instrução, que se encontra centrada nos objetivos, nos conteúdos, nas atividades e, principalmente, na avaliação para o controle de resultados (PACHECO, 2005; PACHECO; PEREIRA, 2007).

Durante a década de 1960, surgiram novas formas de interpretação do currículo (SILVA, 2006; PACHECO; PEREIRA, 2007) e as primeiras críticas à visão tradicional. Com o surgimento de movimentos sociais e culturais influenciados pelas ideias marxistas, os estudos sobre o currículo seguiram duas linhas de pesquisa: currículo centrado nos conteúdos (pedagogia crítica) e currículo com ênfase nas experiências de lutas da classe (SILVA, 2006). Alguns pensadores deste novo campo se destacaram como Apple e Giroux nos Estados Unidos, Althusser, Bourdieu e Passeron na França, e Paulo Freire no Brasil (SILVA, 2006; SANTOS, 2010; PINHEIRO, 2009).

É importante recordar que somente a partir da década de 1980 que os debates sobre os problemas curriculares se intensificaram no Brasil no sentido de transformar o ensino tecnicista em um ensino de cunho progressista (PINHEIRO, 2009). Nesta mesma época, a reforma do sistema educacional também aconteceu em Portugal "marcada pela descentralização, autonomia, participação, identidade e projecto" (PACHECO; PEREIRA, 2007, p. 208) como possibilidade de uma transformação social e construção de uma escola autônoma, crítica e participativa.

De acordo com a visão crítica do currículo, a educação assumiu um lugar de condicionamento e reprodução da cultura dominante, tendo como base apenas a transmissão do conhecimento e as relações de poder. Por isso, é fundamental questionar as desigualdades existentes no sistema de ensino que foram preconizadas pela visão tradicional e tecnicista e, a partir desse ponto, pensar em um ensino que seja capaz de formar os estudantes como sujeitos autônomos, preparando-os para obter uma visão crítica do meio que os cerca visando à possibilidade de transformar sua própria realidade.

As teorias pós-críticas, fundamentadas no pós-estruturalismo ou pós-modernidade, surgiram no contexto educacional para expandir e ampliar a visão crítica de currículo anteriormente existente, dando ênfase às "conexões 
entre saber, identidade e poder"(SILVA, 2007, p.147). Nessa perspectiva, temas como, por exemplo, gênero, raça, sexualidade, multiculturalismo e diferenças étnicas, foram abordados e aprofundados, bem como os espaços político e social dentro da escola foram ampliados.

No sentido apontado, pensar em um conceito único e universal para o currículo a partir de uma teoria em particular, sem considerar todo o desenvolvimento histórico dos estudos curriculares, não corresponderá à realidade. Oliveira (2006) argumenta que a visão conceitual de currículo ainda está enraizada como um conjunto de conteúdos programáticos constituídos para descrever os conteúdos das disciplinas escolares, visão que se apresenta como reducionista e tradicional.

Moreira (2007) acrescenta que ao se levar em conta os fatores socioeconômicos, cultuais e políticos, o conceito de currículo relacionado às atividades organizadas pelas instituições escolares poderá ter diversas concepções, considerando qual ponto de vista teórico ou posicionamento se adote. Para este autor, o currículo pode ser entendido como:

(a) os conteúdos a serem ensinados e aprendidos; (b) as experiências de aprendizagem escolares a serem vividas pelos alunos; (c) os planos pedagógicos elaborados por professores, escolas e sistemas educacionais; (d) os objetivos a serem alcançados por meio do processo de ensino; (e) os processos de avaliação que terminam por influir nos conteúdos e nos procedimentos selecionados nos diferentes graus da escolarização. (MOREIRA, 2007, p. 18)

Algumas das definições expostas apresentam características comuns por apresentarem um conjunto de experiências educativas e de aprendizagem vivenciadas no contexto escolar. No que se refere à definição (b) de Moreira (2007), alude diretamente às experiências escolares e de aprendizagem (RIBEIRO, 1990). A definição (e) de Moreira, (2007) induz a um entendimento da influência dos meios de avaliação (relação de poder) em indicar o que é necessário ser aprendido. Para Gerard e Roegiers (2011), os processos de avaliação atrelados ao currículo possuem tanto aspectos positivos como negativos; o primeiro aspecto se relaciona à eficácia e à equidade dos sistemas educativos e, o segundo, ao risco de ocultar o que os alunos aprenderam de fato.

Diante dos conceitos e visões teóricas discutidos sobre o desenvolvimento curricular e os da época atual, em que se estabelece o domínio tecnológico nos diferentes setores da sociedade, pergunta-se: quais mudanças são necessárias no currículo escolar para que a tecnologia seja efetivamente integrada no cotidiano da escola? Há, de fato, a necessidade de modificação 
ou apenas adaptação ao contexto tecnológico? Quais benefícios seriam alcançados? E ainda: o que é importante e como aprender dentro do contexto tecnológico vivenciado atualmente?

Consideram-se tais reflexões importantes na busca por uma reorientação curricular e por práticas educativas a partir das realidades vivenciadas e desenvolvidas no contexto escolar, pois, entende-se que os currículos sejam "orientados pela dinâmica da sociedade" (MOREIRA, 2007, p. 9) e que o conhecimento que o constitui esteja envolvido com a identidade do indivíduo (BARRETO, 2005). Entretanto, pondera-se que não se devam deixar de lado as teorias críticas e pós-críticas que o fundamentam, pois essas possibilitam a ampliação do conceito e poderão permitir a elaboração de novas ideias.

Por fim, busca-se um currículo coerente, sendo necessário, para isso, de acordo com Beane (2000), envolver "a manutenção de relações visíveis entre os propósitos e as experiências de aprendizagem cotidianas" (p. 47), ou seja, as experiências de aprendizagem são articuladas de acordo com o contexto e a integração das tecnologias ao ambiente escolar facilitará a organização e articulação das experiências de aprendizagem.

\section{EM BUSCA DE UM WEBCURRÍCULO}

O termo webcurrículo já vem sendo utilizado e debatido por pesquisadores e, refere-se à maneira como tecnologia e currículo se relacionam (ALMEIDA; SILVA, 2011; ALMEIDA; VALENTE, 2012), com a intenção da integração das tecnologias - digitais abertas, móveis, interativas, conectadas à Internet - na educação. Bona et al. (2011, p. 1941) explicam webcurrículo da seguinte forma:

O termo "Web" representa a possibilidade de utilizar a tecnologia digital como forma de produzir e compartilhar o conhecimento no mundo complexo em que vivemos, enquanto, o termo "Currículo" representa todas as relações que os sujeitos estabelecem com esse conhecimento.

Na direção indicada por Bona et al. (2011), as duas entidades tornam-se imbricadas no desenvolvimento das atividades pedagógicas com o propósito de possibilitar a professores e alunos, a utilização da tecnologia com um único fim, o de aprender (SANCHEZ, 2002, 2003).

Dessa maneira as relações entre currículo e tecnologias se estabelecem para além dos meios e envolvem as mensagens, os contextos e os significados construídos, com a preocupação diretamente na aprendizagem. 
Considerar o currículo como construção social, política e histórica se constitui na própria ação por meio de TDIC. Assim, como apresentado por Almeida e Valente (2012), explorar os potenciais da TDIC para desenvolver atividades curriculares nas diferentes áreas do conhecimento, possibilitará ao professor "entender e identificar os conhecimentos do senso comum" (p. 58) dos alunos e, com isso, elaborar estratégias didáticas que o auxiliem na compreensão do conhecimento científico.

Sabe-se, porém, que integrar a tecnologia ao cotidiano escolar para inserir a escola na cultura digital não é tarefa simples, pois exige que o professor tenha diferentes saberes e saiba relacioná-los entre si. De acordo com Coutinho (2011), os conhecimentos envolvidos para a efetiva integração das TDIC ao currículo devem ajustar três níveis de conhecimento: científico ou dos conteúdos, pedagógico e tecnológico ${ }^{3}$. Pergunta-se, entretanto: como combinar os três saberes para que haja integração curricular? Segundo a autora, há a necessidade de investimentos para uma adequada capacitação do professor e para a mudança de sua atitude do mesmo frente aos novos desafios.

Pinheiro (2012) acredita que uma adequada formação do professor no sentido de que reflita sobre os novos desafios e se torne agente de mudança só acontecerá quando o currículo dessa formação for construído com base nas teorias crítica e pós-crítica, pois serão elas que possibilitarão essa reflexão sobre sua própria práxis e sobre a realidade social a que pertence. Investigadores como Santos e Borges (2009) e Alves e Carvalho (2011), que também compartilham o mesmo pensamento, asseguram a necessidade dessa capacitação e acentuam o papel do professor tanto como agente de mudanças da estrutura curricular bem como na efetiva integração das TDIC ao currículo. Mas, o que realmente significa integrar as tecnologias ao currículo? É imperativo buscar o seu significado para refletir como a integração poderá ocorrer na prática cotidiana do ambiente escolar.

Partindo-se dessa premissa, recorre-se inicialmente aos dicionários para buscar o significado do termo "integrar". De acordo com o Dicionário da Língua Portuguesa Houaiss, a palavra "integrar"tem vários significados como, por exemplo, "tornar inteiro, completar, incorporar-se, adaptar-se". Por outro lado, o dicionário inglês Merriam-Webster Online: Dictionary and Thesaurus, define integrar como "combinar (duas ou mais coisas) para formar ou criar algo". O Dicionário de Língua Espanhola da Real Academia Espanhola define o mesmo termo como "constituir um corpo, fundir dois ou mais conceitos em um só". 
As definições apresentadas permitem deduzir que o termo "integrar" está diretamente relacionado com a ideia de "formar um todo" ou "conceito único" a partir dos conceitos subjacentes. Logo, integrar as tecnologias ao currículo é fazer com que as TDIC estejam incorporadas de tal forma que não haja mais dissociação entre as tecnologias digitais e o currículo, é reescrevê-los como único e adaptado aos novos contextos da sociedade.

Na visão de Bento Silva (2001), a integração está relacionada às estratégias e ao pensamento estratégico utilizados para conceber um conjunto de ações para se alcançar o melhor resultado. Neste caso, busca-se em primeiro lugar, compreender o porquê da integração e como ela deverá ser realizada. Para esse autor, as estratégias de integração precisam estar relacionadas com ao projeto curricular, com a convergência entre pensamento pedagógico e conhecimento do professor e, finalmente, devem estar inseridas de forma a promover uma renovação pedagógica da escola.

Sanchez (2003) faz uma diferenciação sobre o que é e o que não é integração curricular das tecnologias no meio escolar, a saber: apenas utilizar as TDIC não é sinônimo de integração, sendo que para a integração ocorrer de fato, é necessário existir harmonia e funcionalidade entre tecnologia e currículo, com aulas preparadas e finalidades específicas do conteúdo que se deseja ensinar. Assim, é fundamental combinar tecnologia e ensino em uma experiência produtiva, no sentido de mover o aluno para um novo entendimento sobre o objeto de estudo.

A combinação mencionada, segundo Merril et al. (apud Sanchez, 2003, p. 54), deve ser realizada entre as TDIC e os procedimentos do ensino tradicional. Esse tipo de pensamento pode ser um começo, mas não o suficiente para promover a aprendizagem do aluno, pois se não haver uma concepção clara sobre o uso da tecnologia e uma reflexão com base nas teorias crítica e pós-crítica sobre os processos de aprendizagem, essa combinação poderá representar o perigo de efetivar-se a repetição do que já estava sendo realizado, contexto no qual a tecnologia aparece somente como um "enfeite" ou um meio para a transmissão do conhecimento já consolidado.

As tecnologias digitais integradas ao currículo devem ser utilizadas para estimular o desenvolvimento da aprendizagem e propiciar

[...] a articulação dos contextos de formação e aprendizagem com as situações de experiências autênticas, potencializando o desenvolvimento do currículo como construção permanente de práticas intencionais, com significado cultural, histórico e social. (ALMEIDA; VALENTE, 2012, p. 60) 
Para Almeida e Assis (2011), o uso de tecnologias digitais como tecnologias móveis ou a utilização da web 2.0 em práticas de ensino, aprendizagem e pesquisa são consideradas como inovadoras na educação. Segundo as autoras, a utilização da web 2.0 poderá proporcionar a inovação pedagógica desde que vários fatores sejam a ela relacionados, como por exemplo, a utilização de abordagens pedagógicas que tenham concepções de uma educação transformadora.

Diante do exposto, questiona-se: que procedimentos devem ser tomados no sentido de reconstruir o currículo da era do lápis e papel para o currículo da era digital e torná-lo um webcurrículo? O webcurrículo será uma inovação ou apenas uma adaptação aos novos contextos? Na opinião de Pestana e Pacheco (2013), o uso das tecnologias para uso pedagógico somente poderá ser considerado como inovação quando perspectivas construcionistas forem privilegiadas em sua constituição. Logo, ter presente as tecnologias na sala de aula não representa uma mudança pedagógica (ALMEIDA; VALENTE, 2011), ou seja, requer uma mudança na atitude do professor e na maneira como trabalha em sala de aula conforme preconizado por Coutinho (2011).

Assim, as questões que se apresentam nos impulsionam a discussão sobre novas abordagens curriculares, novos métodos pedagógicos, fazendo com que se pense no desenvolvimento profissional do professor, sobre a organização da escola e no desenvolvimento de propostas curriculares voltadas para o uso da tecnologia, sempre no sentido de conduzir a uma inovação educativa.

Entre as implicações pedagógicas de um webcurrículo, surge o entendimento de que o conhecimento não está terminado, mas em processo de produção, exigindo maior criatividade por parte de alunos e professores, dar voz e vez aos alunos e desenvolver novas posturas pedagógicas. Pondera-se, igualmente, que seja imprescindível pensar nas TDIC não apenas como uma ferramenta ou um recurso pedagógico, mas também como linguagem para representação do conhecimento.

\section{CONSIDERAÇÕES FINAIS}

Os estudos para compreender a complexidade da integração das tecnologias digitais ao currículo educacional não são novos. Apesar de avanços significativos alcançados no campo teórico, na prática parece estar longe de ser atingida. Isso se deve a inúmeros fatores e a diferentes esferas de poder. Integrar as TDIC ao currículo inclui investimentos do poder público, 
isto é, investimentos na formação tecnológica (continuada e permanente) do professor, direcionados para a compreensão das relações existentes entre a tecnologia, o ensino e a aprendizagem; para que possibilite a articulação do trabalho pedagógico com o currículo e o oriente a pensar de forma crítica e reflexiva.

Para concretizar a integração entre tecnologia e currículo como discutido no estudo apresentado neste artigo, com a proposição de que ele se apresente como um webcurrículo, é necessário que a escola disponha não somente de instalações e de equipamentos adequados, mas também de acesso à internet em todas as dependências escolares e professores que dominem os três níveis de conhecimento aqui apresentados. É indispensável, da mesma forma, que exista um questionamento constante, dos educadores e da própria sociedade sobre o tipo de cidadão que se quer formar e de qual sociedade se espera para o futuro. Esses e outros questionamentos devem estar presentes na escola e na mente de professores e pesquisadores, no sentido de um caminhar para o desenvolvimento curricular de acordo com as perspectivas desse novo século.

\section{INQUIRIES AND PERSPECTIVES OF CHANGES FOR A WEB-BASED CURRICULUM}

ABSTRACT: This article presents some reflections on the integration of technology into the curriculum. From the curricular concepts and theories as well as the effort to shed light on the meanings of terms such as "integrating" and "innovating", it has the goal of broadening the discussion and directing this effort to achieve the construction of a web-based curriculum. It must be noted that government investment is needed in two main areas: the technological infrastructure of schools and the adequate teachers training. However, for an adequate training program, it is necessary a foundation built with three levels of knowledge (pedagogy, technology, and content) and with curricular critical and post-critical theories.

KEYWORDS: Web-based curriculum. Curriculum theories. Integration. Technologies. 


\section{INVESTIGACIONES Y PERSPECTIVAS DE LOS CAMBIOS EN WEBCURRICULO}

RESUMEN: Este artículo presenta las reflexiones sobre la integración de la tecnología en el currículo a partir de los conceptos y teorías curriculares y la búsqueda de la comprensión de los significados de términos como la integración y la innovación, con el objetivo de ampliar la discusión y la unidad para lograr un webcurrículo. Evidencia también de que, para lograr este objetivo, es necesaria la inversión del gobierno en dos áreas: en la estructura tecnológica de las escuelas y en la formación adecuada del profesorado. Sin embargo, se señala que para una formación adecuada, se debe basarse en los tres niveles de conocimiento (pedagógico, tecnológico y contenido) y en las teorías críticas y en las críticas post-curricular.

PalABRAS CLAVE: Webcurrículo. Teorías curriculares. Integración. Tecnologías.

\section{NOTAS}

1) Agradecimento à CAPES pelo apoio financeiro através do Programa de Bolsa de Estudos para o Doutorado Pleno no Exterior.

2) Termo apresentado pela Dra Maria Elizabeth Bianconcini de Almeida, em palestra no I Seminário WebCurrículo realizado na PUC-SP em 2008.

3) Os três níveis de conhecimento foram definidos por Punya Mishra e Matthew Koehler como TPACK - Technological Pedagogical Content Knowledge (COUTINHO, 2011).

\section{REFERÊNCIAS}

ALMEIDA, M. E. B.; ASSIS, M. P. Integração da web 2.0 ao currículo: a geração web currículo. Revista digital La educ@cion, no 45, 2011. Disponível em: <https://www. educoas.org/portal/La_Educacion_Digital/laeducacion_145/articles/ART_bianconcini_ES.pdf $>$. Acesso em: 02 fev. 2014.

ALMEIDA, M. E. B.; SILVA, M. G.M. Currículo, tecnologia e cultura digital: espaços e tempos de web currículo. Revista e-curriculum, São Paulo, v. 7, n. 1, 2011. Disponível em: <http://revistas.pucsp.br/index.php/curriculum>. Acesso em: 10 fev. 2014.

ALMEIDA, M. E. B.; VALENTE, J. A. Integração currículo e tecnologias e a produção de narrativas digitais. Currículo sem Fronteiras, v. 12, n. 3, p. 57-82, set./dez. 2012.

ALVES, T. P.; CARVALHO, A. B. G. Os laptops educacionais e a cultura digital no município de Caetés (PE). X Congresso Nacional de Educação. Curitiba: Educere, 2011. 
BARRETO, E. S. S. Têndencias recentes do currículo na escola básica. São Paulo: Fundação Carlos Chagas, 2006.

BEANE, J. A. O que é currículo coerente? In: PACHECO, J. A. (Org). Políticas de integração curricular. Porto: Porto Editora, 2000. 188 p.

BONA, Aline Silva de. et al. Concepções de Currículo, Projetos de Aprendizagem e Interação no Projeto UCA/RS. In: $22^{\circ}$ Simpósio Brasileiro de Informática na Educação e 17 Workshop de Informática na Escola - Aracajú, 2011.

CERVO, A. L.; BERVIAN, P. A. Metodologia Científica: para uso dos estudantes universitários. 3. ed. São Paulo: McGraw-Hill do Brasil, 1983.

COUTINHO, C. P. TPACK: em busca de um referencial teórico para a formação de professores em tecnologia educativa. Revista Paidei@, Santos, v. 2, n. 4, jul. 2011.

COUTINHO, C. P. Tecnologia educativa e currículo: caminhos que se cruzam ou se bifurcam? Revista Teias, v. 8, n. 15-16, p. 1-16, jan./dez., 2007.

GERARD, F.M.; ROEGIERS, X. Currículo e avaliação: ligações que nunca serão suficientemente fortes. In: ALVES, M. P; KETELE, J. M. (Org.). Do currículo à avaliação: da avaliação ao currículo. Porto: Porto Editora, 2011.

MARCONI, M. A.; LAKATOS, E. M. Metodologia científica: ciência e conhecimento científico. Métodos Científicos, teorias, hipotéses. São Paulo: Atlas, 2007.

MIRANDA, Guilhermina Lobato. Limites e possibilidades das TIC na educação. Sísifo Revista de Ciências da Educação, Lisboa, n. 3, p. 41-50, maio/ago. 2007.

MOREIRA, A. F. B. Indagações sobre currículo: currículo, conhecimento e cultura. Brasília: Ministério da Educação; Secretaria de Educação Básica, 2007. 48 p.

OLIVEIRA, I. B. de. Tendências recentes dos estudos e das práticas curriculares. In: Construção coletiva: contribuições à educação de jovens e adultos. Brasília: UNESCO, MEC, RAAAB, 2006.

PACHECO, J. A.; PEREIRA, N. Estudos curriculares: das teorias aos projectos de escola. Educação em Revista, Belo Horizonte, n. 45, p. 197-211, jun. 2007. Disponível em: <http://dx.doi.org/10.1590/S0102-46982007000100011>. Acesso em: 11 fev. 2014.

PESTANA, T. C.; PACHECO, J. A. Currículo, tecnologias e inovação: para uma discussão da aprendizagem em contextos educacionais. Revista Linhas, Florianópolis, v. 14, p. 45-58, jul./dez. 2013.

PINHEIRO, G. C. G. Teoria curricular crítica e pós-crítica: uma perspectiva para a formação inicial de professores para a educação básica. Analecta, v. 10, n. 2, p. 11-25, jul./dez. 2009.

RIBEIRO, A. C. Desenvolvimento curricular. Lisboa: Texto Editora, 1990. 184 p. 
SANCHEZ, J. Integración Curricular de las TICs: Conceptos y Ideas. Santiago: Universidad de Chile, 2002.

SANCHEZ, J. Integración Curricular de TICs: conceptos y modelos. Revista Enfoques Educacionales, Santiago de Chile, v. 5, n. 1, p. 51-65, 2003.

SANTOS, M. B. F.; BORGES, M. K. Laptops educacionais e o currículo: impressões sobre uma escola piloto do projeto UCA - Brasil. In: SÁNCHEZ; J. Nuevas Ideas en Informática Educativa - volumen 5. Chile: TISE, 2009. p. 43-53.

SANTOS, P. P. dos. A formação do educador social atuante no espaço rua: contribuições de Freire, Apple e Giroux. VI Encontro de Pesquisa em Educação da UFPI. Piauí, 2010. Disponível em: <http://www.ufpi.br/subsiteFiles/ppged/arquivos/files/ Vl.encontro.2010/GT.1/GT_01_04.pdf>. Acesso em: 02 fev. 2014.

SILVA, Bento. A tecnologia é uma estratégia. In: DIAS, P.; FREITAS, V. (Org.). Actas da II Conferência Internacional Desafios 2001. Braga: Centro de Competência da Universidade do Minho do Projecto Nónio, 2001. p. 839-859.

SILVA, M. A. História do Currículo e Currículo como Construção Histórico-cultural Trabalho Comp. In: VI Congresso luso-brasileiro de História da Educação. Uberlândia: 2006. Anais do VI Congresso Luso-Brasileiro de História da Educação. Uberlândia: EDUFU, 2006. v. 1. 2006. p. 4820-4828.

SILVA, T. T. Documentos de Identidade: uma introdução às teorias do currículo. 2 ed. Belo Horizonte: 2007. 156 p.

ZABALA, A. A organização dos conteúdos. In: ZABALA, A. (Org.). A prática Educativa: Como ensinar. Artmed. Porto Alegre: Artmed, 1998.

VALDIR ROSA: Doutorando em Ciências da Educação na especialidade Tecnologia Educativa pela Universidade do Minho. Mestre em Ciências Naturais e Matemática pela Universidade de Blumenau. Graduado em Física pela Universidade de Maringá.

E-mail:val_rdim@hotmail.com 